\title{
El aprendizaje de las ciencias
}

\section{LUIS JAVIER NARVAEZ ZAMORA*}

Más de un lustro de trabajp dedica do a la experimentación sobre la implementación del modelo construcllalita en la región surcolombiana, tanto a nivel de pregrado y postgrado en educación básica, media y superior; me obligan a postular los beneficios y la efiracia del constractivismo humano en la adquisición de aprendizaje significativo.

Este tipo de aprendizaje le alcanza una persona cuando en una actividad consciente y autónoma, logra vineular a su estructura cognitiva preexistente, nuevas regularidades de la realidad (naturaleza o sociedad) de manera relevante, no arbitraria ni memorística: este aprendizaje depende por un lado de la disposición al conocimiento, la calidad de los materiales de aprendizaje y por otra parte de la capacidad que tiene el aprendiz de procesar información almacenada, constituida como constructo personal, con el cual podrá explicar una nueva experiencia.

La didáctica de las ciencias naturales debe centrarse en buscar los mecanismos útiles, constituidos en el puente que permita relacionar los preconceptos del aprendiz con una nueva información, tarea que al final logra modificar su estructura cognitiva o entramado conceptual.

Aprender ciencia implica a la vez reconocer nuevas regularidades en hechos u objetos, invención de nuevos o extensión de antiguos conceptos, aceptando nuevas relaciones proposicionales y en los saltos más creativos paradigmáticos, una reestructuración sustantiva de tramas conceptuales de orden superior.

La subsunción de nuevos conceptos origina una jerarquía conceptual idiosincratica fácilmente observable en instrumentos didácticos valiosos tales como los mapas conceptuales ovas v-heurísticas, donde se plasma la teoría asimilacionista Ausubeliana, sobre la cual se fundamenta el Constructivismo Humano.

Los aspirantes a licenciados en Biología y Química de la Universidad Surcolombiana tienen la exigencia pedagógica de experimentar nuevas estrate-

- Licenciado en Biología y Química: Espesalalista en Docencia de la Biología. Profesor catedrático, adscrito al Programa de Licenciatura en Biología y Química, Universidad Surcoiombiana. 


\section{5}

Paideia Surcolombiana

a dácticas en ciencias naturales de - alusión y aplicación mundial en c- - do je las dos últimas décadas. a Universidad Pedagógica Nacioa zionera en el país confrontando - usus esquemas constructivistas चr:- sus pregrados como en sus zenados, donde el sabor del aprensignificativo en ciencias a partir z $=$ zeconceptos se encuentra im- preso en sus líneas investigativas a nivel de docencia en Química y Biología.

El uso de las preconcepciones o ideas previas, las cuales son el producto de la experiencia cotidiana con las que se puede asumir una postura epistemológica, se constituye en la base de la teoría de la asimilación resumida en el mapa conceptual siguiente:

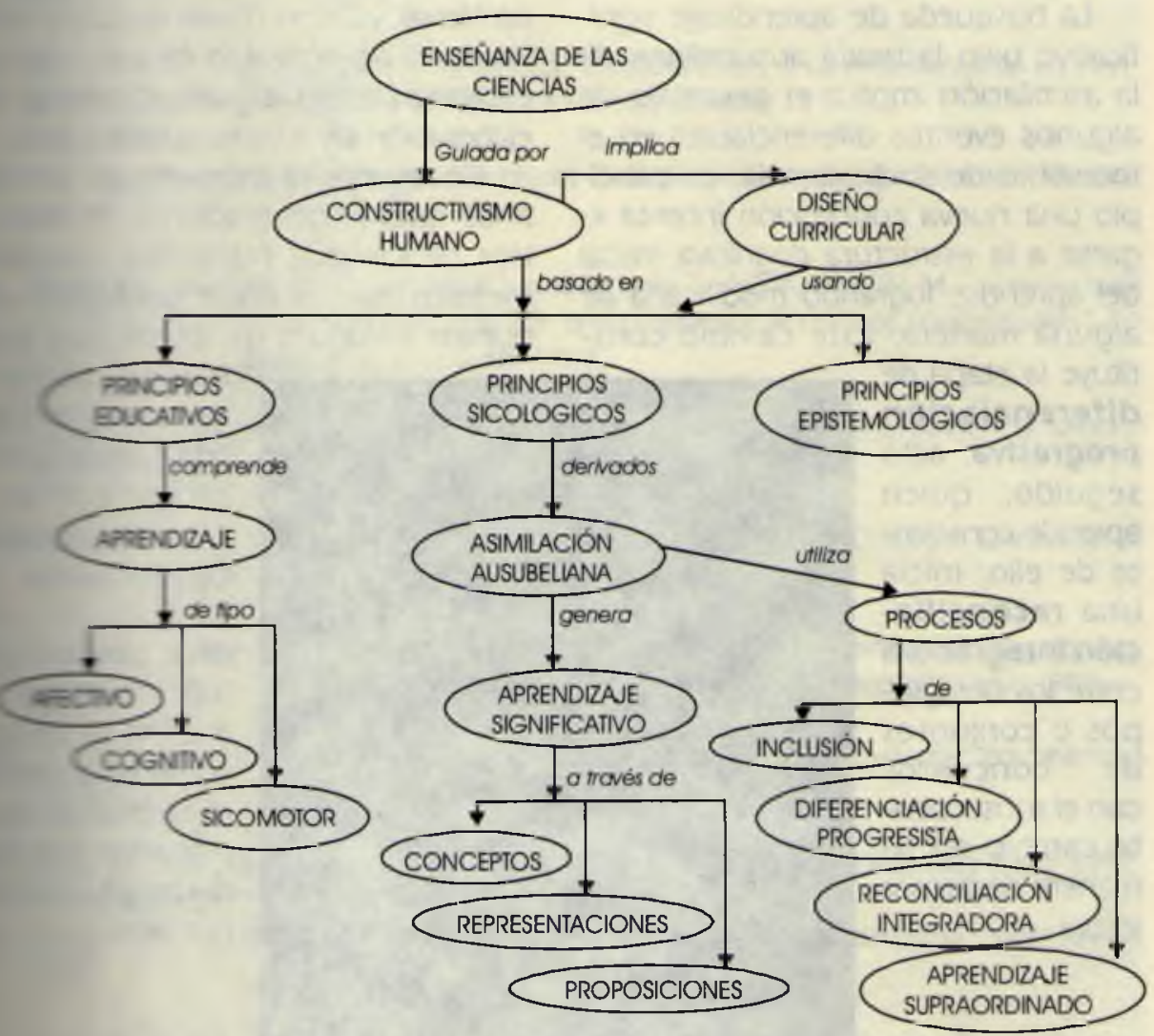

experiencia del microdiseño ar aje se traduce en la formufal plan de práctica docente, la nsutuye en un trabajo de graun aspirante a Licenciado en Química; debe definir un eneticdológico muy claro y efec- tivo para que su labor docente tenga un rumbo intencionado y autónomo.

La posición constructivista la propongo como mecanismo alterno al paradigma inductivista que ha manejado la educación mundial por más de setenta años en el siglo pasado, ampa- 


\section{6}

Universidad Surcolombiana

rado en los puntos de vista sobre la naturaleza del conocimiento positivista con su lógica hermenéutica de que la verdad aguarda en la naturaleza.

Los conceptos son regularidades percibidas en los hechos u objetos para que quien aprende los etiquete con un lenguaje codificado; la creación del conocimiento es la búsqueda de regularidades o de las regularidades de los registros de los hechos.

La búsqueda de aprendizaje significativo bajo la teoría ausubeliana de la asimilación implica el desarrollo de algunos eventos diferenciables en el momento de su ocurrencia: en principio una nueva concepción intenta ligarse a la estructura cognitiva inicial del aprendiz, logrando modificarla de alguna manera; este cambio constituye la etapa de

\section{diferenciación progresiva, acto} seguido, quien aprende consciente de ello, inicia una reconciliación integradora entre los dos grupos o conjuntos de conceptos con el subsecuente cambio en su manera de pensar inicial.
El nuevo aprendizaje a nivel fisiológico, implica no solo una relación neurona-neurona sino que a ellas se ligan decenas de miles de diversas regiones cerebrales permutables, en las sinapsis se forman canales transmisores sinápticos, involucrando gran cantidad de axones, los cuales se activan a diferentes potenciales de acción generados por esfuerzos de evocación y relación conceptual, tal como lo han demostrado Novak y Dunn (1996) en sus observaciones de actividad neural usando escanners encefalográficos durante la elaboración de mapas conceptuales.

Finalmente la intención es formar a las nuevas generaciones de maestros de Ciencias Naturales, comprometidos con la implementación de nuevos enfoques metodológicos que hayan demostrado su potencialidad relevante para generar cambios cognitivos, conductuales y actitudinales; es decir, cambios significativos en la manera de pensar como lo ha hecho el aprendizaje significativo a la luz del constructivismo humano. 
Paideia Surcolombiana

\section{BIBLIOGRAFIA}

AUSUBEL, David, P NOVAK, Joseph D. HANNESIAN, Helen. Psicología educativa: Un cunto de vista cognoscitivo. Tercera edición. Editorial Trillas, México. 1987.

2 CARRETERO, Mario. El desarrollo de la adolescencia y la juventud: operaciones formaes. Editorial Edelvives. Madrid. 1992

3 J-L Daniel. "Psicología educativa y didáctica de las ciencias. Los procesos de enseñanza-zprendizaje como lugar de encuentro" en Infancia y Aprendizaje, 62-63, 171-186, $\because$ adrid, 1993.

- IL Daniel. CARRASCOSA, J. y MARTínEZ TORREGROSA, J. La enseñanza de las cienàs en la educación secundaria. Editorial Horsori. Madrid, 1991.

5 GOMEZ Crespo, Miguel Ángel. Materiales Didácticos, Química, Bachillerato. Madrid, UEC. 1993.

E GM:MEZ Crespo, Miguel Ángel. POZO, José Ignacio. SANZ, A. LIMÓN, M. "La estructura Je las conocimientos previos en química: una propuesta de núcleos conceptuales". En in escigación en la escuela. 18, 23-40. 1989

I 6:4EZ Crespo. Miguel Ángel. POZO, José Ignacio. Aprender y enseñar ciencia. Segunda edición. Ediciones Morata, Madrid. 2000.

nurN. Thomas. La estructura de las revoluciones científicas. Chicago: University of Inicago Press. 1987.

\ARVAFZ Z, Luis Javier. Un enfoque constructivista para el aprendizaje de algunos anceptos en Ciencias Naturales. Tesis de grado. Universidad Surcolombiana. 1994.

" . D.A K, Joseph J. "Concept mapping a strategy for organizing knowledge" en: Learning sernce in schools. Hillsdale, New York. Erlbaum. 1995.

Joseph J. GOWIN, B. D. Learning to learn. Cambridge University Press. 1992.

* ZCa José Ignacio. Aprendices y maestros. Madrid. Editorial Alianza/Sicología Minor. 1998

4 GOTIKY. L.S. Myshelenie i rech. Traducción al castellano M.M. Rotger: Pensamiento y - Euze. Ediciones La Pléyade. 1978. 


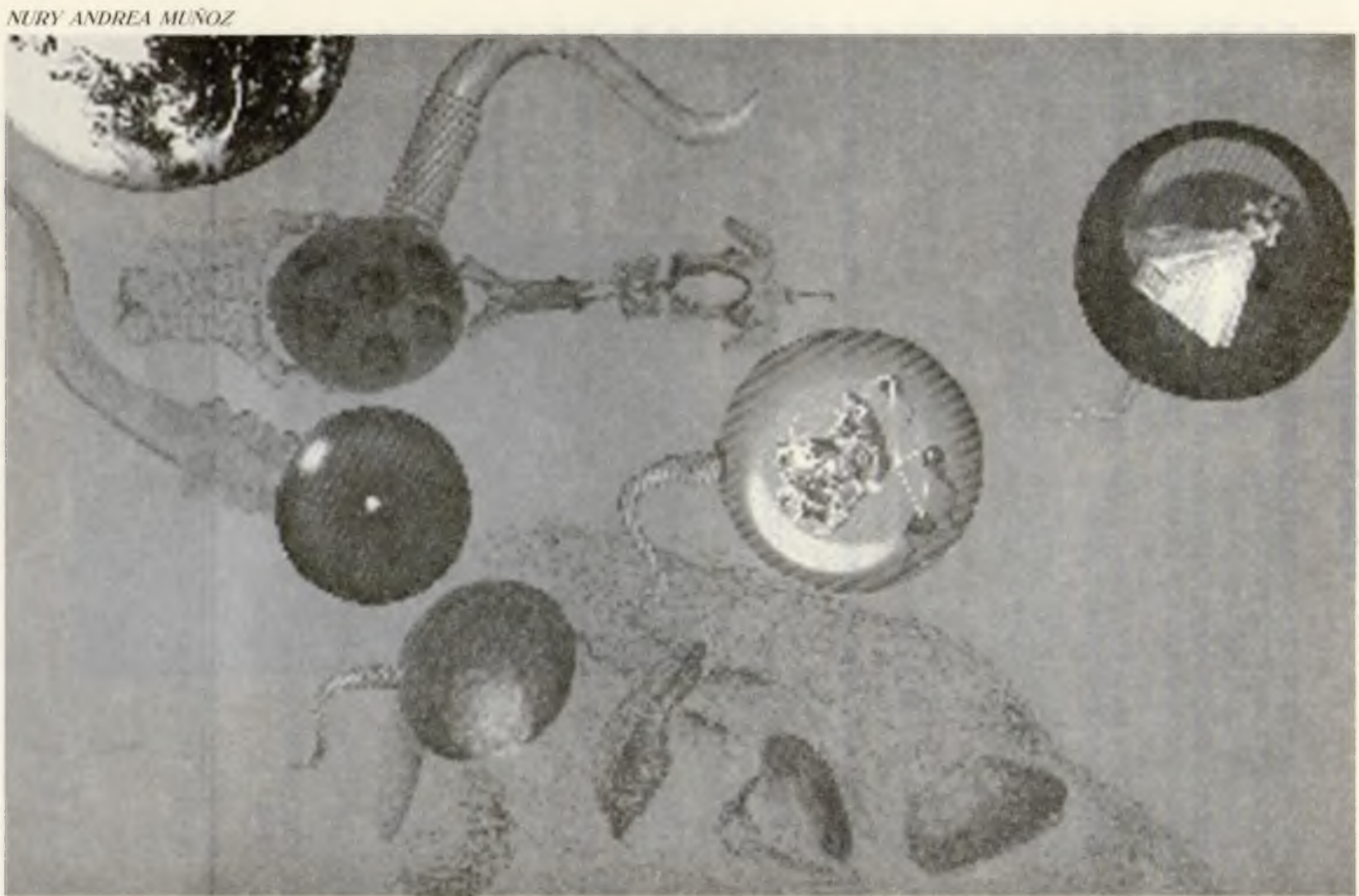

